Transactions of the SDPS:

Journal of Integrated Design and Process Science

16 (3), 2012, 1-5

DOI 10.3233/jid-2012-0022

http://www.sdpsnet.org

\title{
Editorial: Theories Of and About Design
}

Since the "design method movement" began in Europe in 1960's (Cross, 1984), design research has moved along two closely related directions: design theories of how to design, which are often called design methodology, and design theories about what is design, which take design as a phenomenon for scientific investigation. For the former, one can find systematic design methodologies such as synthesis method by Alexander (1964; 1977), systematic design (Hubka \& Eder, 1988; Pahl \& Beitz, 1984), axiomatic design (Suh, 1990), TRIZ (Altshuller, 1984), function based design (Erden et al., 2008; Gero, 1990; Goel \& Stroulia, 1996; Stone \& Wood, 2000; Tomiyama et al., 1993), c-k theory (Hatchuel \& Weil, 2003), affordance-based design (Maier \& Fadel, 2009), and environment-based design (Zeng, 2004; 2011). For the latter, one can find philosophical and logical investigation into design (Cross, 2006; Eekels, 2000; Roozenburg \& Eekels, 1995; Schön, 1983; Simon, 1969; Zeng \& Cheng, 1991), cognitive and experimental research (Goldschmidt, 1994; Suwa et al., 1998; Visser, 2006), and mathematical theories for representing and modeling design (Braha \& Maimon, 1998; Salustri \& Venter, 1992; Tetsuo Tomiyama, 1987; Tomiyama, et al., 1993; Yoshikawa, 1981; Zeng, 2002; Zeng \& Gu, 1999a; Zeng \& $\mathrm{Gu}, 1999 \mathrm{~b})$.

In conducting design research, researchers have applied different research methodologies such as observations, experiment, and deduction (Blessing \& Chakrabarti, 2009; Frey \& Dym, 2006; Reich, 1995), and have investigated different aspects of design (Sim \& Duffy, 2003). The ultimate goal of design research is to discover and/or develop orders underlying or upholding design activities (Horváth, 2004). This special issue includes six papers focusing on development, application, or validation of theories of and about design.

The first paper included in this issue, titled "Fundamentals of design and deployment of large complex systems: OLEV, MH, and Mixalloy", is contributed by Prof. Nam Suh. In early 1980's, Prof. Suh developed his well-known axiomatic design theory (Suh, 1990), which provides two basic principles for a good design. His strong belief in a rational design process has motivated and inspired many design researchers and has significantly influenced the advancement of design science. In this paper, Prof. Suh demonstrates the power of rational design and system development using the axiomatic design theory through three case studies. The case studies involve large and highly innovative systems: On-Line Electric Vehicle (OLEV), Mobile 12 Harbor $(\mathrm{MH})$, and Mixalloy. In contrast to a widely observed phenomenon that many major corporations often miss the delivery dates of their newly developed systems and exceed the originally estimated development cost, these three innovative systems were developed and deployed at minimum cost and on time. The major reason behind their successes was because in each case the entire system had been designed based on a firm theoretical foundation for system development and rigorous checking of the system architecture. These case studies, among many other success stories in applying the axiomatic design theory, show that axiomatic design theory can be used to solve complex transdisciplinary problems. 
The second paper by Cascini, titled "TRIZ-based anticipatory design of future products and processes", surveys the most relevant contributions in using a design methodology TRIZ to forecast technology evolutions. In achieving the objective of shortening the lead time to deliver innovative products to their customers, it is critical to decouple strategic conceptual design activities from embodiment and detail design tasks. Conceptual design can be seen as an effort driven by the anticipation of future technical scenarios whereas embodiment and detail design is focused more on the configuration and the customization of the concepts formulated during the conceptual design stage. This decoupling of strategic conceptual design can be beneficial to mitigate the risks in strategic decision making in new product development. After a detailed analysis of the evolution of technical systems, the author introduces the approaches to integrating the forecast of future technical scenarios with the design of technical solutions. Furthermore, ongoing research activities are briefly summarized regarding the combination of TRIZ with other methodologies for technology forecasting. Finally, the author concludes the paper with an extensive discussion about the strengths and weaknesses of TRIZ in technology forecast.

While the first two papers are focused on theories of design, the third paper presents a theory about design, which aims to interpret design phenomena following an axiomatic approach. Nguyen and Zeng, in their paper titled "A theoretical model of design creativity: nonlinear design dynamics and mental stresscreativity relation", propose a theoretical model for creative design. This theoretical model builds on two postulates: 1) design reasoning follows a nonlinear dynamics, which may become chaotic; and 2) there is an inverse U shaped relationship between designer's mental stress and design creativity. The first postulate addresses the relationships among the design problem, design solutions, design knowledge, and other design related information whereas the second postulate relates the design process to the designer's capacity. An interpretation of the roles of sketching in design is derived to show how this theoretical model can be used to study design phenomena. The power of reasoning is a critical component of any proper theory. This paper is one of the first steps leading to such a theory of modeling and understanding design activities.

In the fourth paper, titled "Comparing the strategies and outputs of designers using Algorithm of Inventive Problem Solving, Axiomatic Design, or Environment-Based Design”, Dubois et al. present the results of a study designed to compare the processes followed by practitioners of three design methods: the algorithm of inventive problem solving (Altshuller, 1984), axiomatic design (Suh, 1990), and environment based design (Zeng, 2011) through an experimental studies conducted by three research groups. In the study, a series of three one-day and three three-day design exercises were conducted simultaneously by three international research groups, each focusing on one method. The design exercises presented to designers covered a range of design tasks that spanned multiple disciplines, multiple levels of open-endedness/specificity of the task, and various levels of inventiveness required. The objectives of this comparative study were to establish, from observations of practitioners, the differences and complementarities between the design methods. The comparison showed the complementary nature of the design methods, highlighted their respective strengths, and suggested the outlines of an integrated method based on the main benefit of each. This study could be taken as a starting point to establish benchmarks for the validation of design methodologies.

In the fifth paper, titled "Modeling, evaluation and simulation during the early design stages: toward the development of an approach limiting the need for specific knowledge", Medyna et al. aim to help engineering designers make more informed decisions during the early stages of the design process without wasting time on gathering highly specific knowledge. Specific knowledge refers to knowledge that is linked to a particular field and that not every engineering designer can be expected to have. This paper provides a mathematical analysis of the early design process justifying the use, by engineering designers, of intermediate abstract concepts to move gradually from an initial description of needs to initial solutions. A practical method of combining these concepts for operational use is introduced in the paper. A method for modeling the behavior of early design solutions and representing models in the form of a graph representation and a set of clustered descriptive attributes of the design problem is also 
presented. Reducing the amount of effort needed to acquire specific knowledge is indeed a goal, explicit or implicit, of every methodology for design synthesis.

The last paper, titled "On the transdisciplinary field of humor research", does not appear to fit into the theme of this present issue. However, the editor has decided to include it in this issue for two reasons. First, while design in general is to satisfy a prescribed expectation, humor delivers a 'funny' departure from a predefined expectation. Both design and humor deal with the issue of fitness between an expectation and a delivery. Second, like most of the other papers in this special issue, this paper also presents a well-defined theory assuming properties of a proper theory, particularly for a transdisciplinary field such as design and humor. In the paper, Taylor and Raskin introduce the rationale and theory for rigorous study of humor that provides a foundation for a proper theory of humor and review the existing formal theories of humor. It is discussed in the paper that computers could be programmed to detect and generate humor and determine the patterns of individual humor preferences both for the joke tellers or posters and for the people that comment on jokes. This simulation can be achieved by integrating a computational semantic technology for information and text meaning analysis with theories of humor. Considering the similarities between humor and design, this journal will run a special issue on "Applications and theory on computational creativity" to trigger deeper interactions between these two fields.

Theory driven design and design research have not received the same amount of attention as some of the other efforts in the design research community have. The main reasons for this lack of interest are that the rigorous endeavors are demanded of researchers and that the effort is generally much harder to be recognized by both the design community and the relevant funding agencies. Nevertheless, this is where the significant breakthrough is much needed and could happen in the research field. In publishing this special issue, we would like to encourage more researchers to participate in this challenging journey of developing and applying theories to design and to design research.

\section{References}

Alexander, C. (1964). Notes on the Synthesis of Form. Cambridge, Massachusetts: Harvard University Press.

Alexander, C. (1977). A Pattern Language: Towns, Buildings, Construction. New York: Oxford University Press.

Altshuller, G. S. (1984). Creativity as an Exact Science : The Theory of the Solution of Inventive Problems. In F. H. George (Ed.), Studies in Cyberbetics. New York: Gordon and Breach Science Publishers.

Blessing, L. T. M.\& Chakrabarti, A. (2009). DRM, a Design Research Methodology. London, UK: Springer. doi:10.1007/978-1-84882-587-1.

Braha, D.\& Maimon, O. (1998). A Mathematical Theory of Design: Foundations, Algorithms and Applications. Boston, MA: Kluwer Academic.

Cross, N. (1984). Developments in Design Methodology. Chichester, UK: Wiley.

Cross, N. (2006). Designerly Ways of Knowing (1st ed.). London, UK: Springer.

Eekels, J. (2000). On the Fundamentals of Engineering Design Science: The Geography of Engineering Design Science. Part 1. Journal of Engineering Design, 11(4), 377-397. doi: 10.1080/09544820010000962

Erden, M. S., Komoto, H., Van beek, T. J., D'Amelio, V., Echavarria, E., \& Tomiyama, T. (2008). A Review of Function Modeling: Approaches and Applications. Artificial Intelligence for Engineering Design, Analysis and Manufacturing, 22(2), 147-169. doi: 10.1017/S0890060408000103 
Frey, D. D.\& Dym, C. L. (2006). Validation of Design Methods: Lessons from Medicine. Research in Engineering Design, 17(1), 45-57. doi: 10.1007/s00163-006-0016-4

Gero, J. S. (1990). Design Prototypes: A Knowledge Representation Schema for Design. AI Magazine, 11(4), 26-36.

Goel, A. K.\& Stroulia, E. (1996). Functional Device Models and Model-Based Diagnosis in Adaptive Design. AI EDAM, 10(04), 355-370. doi: 10.1017/S0890060400001670

Goldschmidt, G. (1994). On Visual Design Thinking: The Vis Kids of Architecture. Design Studies, 15(2), 158-174. doi: 10.1016/0142-694X(94)90022-1

Hatchuel, A.\& Weil, B. (2003). A New Approach of Innovative Design: An Introduction to C-K Theory. Proceedings of the 14th International Conference on Engineering Design ICED03, 109-110

Horváth, I. (2004). A Treatise on Order in Engineering Design Research. Research in Engineering Design, 15(3), 155-181. doi: 10.1007/s00163-004-0052-x

Hubka, V.\& Eder, W. E. (1988). Theory of Technical Systems: A Total Concept Theory for Engineering Design (1st ed.). New York: Springer.

Maier, J. R. A.\& Fadel, G. M. (2009). Affordance Based Design: A Relational Theory for Design. Research in Engineering Design, 20(1), 13-27. doi: 10.1007/s00163-008-0060-3

Pahl, G.\& Beitz, W. (1984). Engineering Design. London, UK: Springer.

Reich, Y. (1995). The Study of Design Research Methodology. Journal of Mechanical Design, 117(2A), 211-214. doi: 10.1115/1.2826124

Roozenburg, N. F. M.\& Eekels, J. (1995). Product Design: Fundamentals and Methods. Chichester, UK: John Wiley \& Sons.

Salustri, F. A.\& Venter, R. D. (1992). An Axiomatic Theory of Engineering Design Information. Research in Engineering Design, 8(4), 197-211.

Schön, D. A. (1983). The Reflective Practitioner: How Professionals Think in Action. London, UK: Temple Smith.

Sim, S. K.\& Duffy, A. H. B. (2003). Towards an Ontology of Generic Engineering Design Activities. Research in Engineering Design, 14(4), 200-223. doi: 10.1007/s00163-003-0037-1

Simon, H. A. (1969). The Sciences of the Artificial. Cambridge, Massachusetts: MIT Press.

Stone, R. B.\& Wood, K. L. (2000). Development of a Functional Basis for Design. Journal of Mechanical Design, 122(4), 359-370. doi: 10.1115/1.1289637

Suh, N. P. (1990). The Principles of Design. New York: Oxford University Press, USA.

Suwa, M., Purcell, T., \& Gero, J. (1998). Macroscopic Analysis of Design Processes Based on a Scheme for Coding Designers' Cognitive Actions. Design Studies, 19(4), 455-483. doi: 10.1016/S0142694X(98)00016-7

Tomiyama, T. \& Yoshikawa, H. (1987). Extended General Design theory, Proceedings IFIP WG 5.2 Working Conference on Design Theory for CAD (pp. 95-130). Amesterdam: Elsevier Science Publishers B. V.

Tomiyama, T., Umeda, Y., \& Yoshikawa, H. (1993). A CAD for Functional Design. CIRP Annals Manufacturing Technology, 42(1), 143-146. doi: 10.1016/S0007-8506(07)62412-3

Visser, W. (2006). The Cognitive Artifacts of Designing (1st ed.). New Jersey: Lawrence Erlbaum Associates.

Yoshikawa, H. (1981). General Design Theory and a CAD System Man-Machine Communication in CAD/CAM, Proceedings IFIP WG 5.2 Working Conference. North Holland: Amsterdam. 35-38 
Zeng, Y. (2002). Axiomatic Theory of Design Modeling. Journal of Integrated Design \& Process Science, 6(3), 1-28.

Zeng, Y. (2004). Environment-Based Formulation of Design Problem. Journal of Integrated Design \& Process Science, 8(4), 45-63.

Zeng, Y. (2011). Environment-Based Design (EBD). ASME 2011 International Design Engineering Technical Conferences and Computers and Information in Engineering Conference (IDETC/CIE2011) 237-250. doi:10.1115/DETC2011-48263

Zeng, Y.\& Cheng, G. D. (1991). On the Logic of Design. Design Studies, 12(3), 137-141.

Zeng, Y.\& Gu, P. (1999a). A Science-Based Approach to Product Design Theory Part II: Formulation of Design Requirements and Products. Robotics and Computer-Integrated Manufacturing, 15(4), 341-352. doi: 10.1016/S0736-5845(99)00029-0

Zeng, Y.\& Gu, P. (1999b). A Science-Based Approach to Product Design Theory. Part I: Formulation and Formalization of Design Process. Robotics and Computer-Integrated Manufacturing, 15(4), 331339. doi: 10.1016/S0736-5845(99)00028-9

Editor: Yong Zeng

Concordia Institute for Information Systems Engineering Faculty of Engineering and Computer Science

Concordia University yong.zeng@concordia.ca 